\title{
Order Allocation Research of Logistics Service Supply Chain with Mass Customization Logistics Service
}

\author{
Weihua Liu, ${ }^{1}$ Haitao Xu, ${ }^{1}$ Xinyu Sun, ${ }^{2}$ Yi Yang, ${ }^{1}$ and Yuming Mo ${ }^{3}$ \\ ${ }^{1}$ School of Management, Tianjin University, Tianjin 300072, China \\ ${ }^{2}$ Department of Logistics and Maritime Studies, The Hong Kong Polytechnic University, Kowloon, Hong Kong, China \\ ${ }^{3}$ College of Engineering, Purdue University, Hovde Hall, 610 Purdue Mall, West Lafayette, IN 47906, USA \\ Correspondence should be addressed to Weihua Liu; lwhliu888@163.com
}

Received 23 July 2013; Revised 3 September 2013; Accepted 23 September 2013

Academic Editor: Kannan Govindan

Copyright (C) 2013 Weihua Liu et al. This is an open access article distributed under the Creative Commons Attribution License, which permits unrestricted use, distribution, and reproduction in any medium, provided the original work is properly cited.

\begin{abstract}
This paper studies the order allocation between a logistics service integrator (LSI) and multiple functional logistics service providers (FLSPs) with MCLS. To maximize the satisfaction of FLSPs, minimize the total cost of LSI, and maximize the customized degree, this paper establishes a multiobjective order allocation model of LSSC that is constrained by meeting customer demand, customer order decoupling point, and order difference tolerance coefficient. Numerical analysis is performed with Lingo 12 software. This paper also discusses the influences of scale effect coefficient, order difference tolerance coefficient, and relationship cost coefficient on the comprehensive order allocation performance of the LSSC. Results show that LSI prefers FLSPs with better scale effect coefficients and does not need to set an extremely high order difference tolerance coefficient. Similarly, setting a high relationship cost coefficient does not necessarily correspond to better results. For FLSPs, the continuous improvement of large-scale operational capacity is required. When the comprehensive order allocation performance of the LSSC is high, the LSI should offer cost compensation to improve the satisfaction of the LSSC.
\end{abstract}

\section{Introduction}

Outsourcing service, such as information technology services, financial services, and logistics services, has become increasingly popular in recent years due to the fact it appears to be more profitable. Many service integrators and functional service providers develop a long-term service purchasing/supplier relationships to satisfy customers demand and obtain more profit with integrated services and then form a service supply chains (SSC). Specially, in a logistics service supply chain (LSSC), a logistics service integrator (LSI) provides customized logistics services by integrating the service capacities of multiple functional logistics service providers (FLSPs) [1]. For instance, Baogong Logistics Company, one of the largest LSI in China, integrates more than 500 storage companies, more than 1,200 highway transportation companies, and over 500 manual loading and unloading companies as its FLSPs and then accomplishes the integrated logistics services for its customers such as Procter \& Gamble, and Philips.
In recent years, customer requirements for specialized and customized logistics services have increased. Many logistics enterprises have also begun considering a change in logistics service mode. These logistics enterprises have attempted to provide mass customization logistics service (MCLS) instead of only mass logistics service [2]. MCLS is one of the most important trends in logistics service. The capability of offering MCLS to customers has become the key to improving market competitiveness. In the MCLS environment, many logistics enterprises spontaneously form a logistics service supply chain (LSSC) through unions and integrations to meet customized demand and offer large-scale services $[1,3]$. As the core enterprise of LSSC, the logistics service integrator (LSI) integrates the advantages of other functional logistics service providers (FLSPs) in different processes and different functions and delivers the integrated service to customer. For instance, on 11 November, 2011, more than 2.67 million packages were delivered all over the country by the Yuantong Express Company in China; this number is 
more than four times the number of packages delivered on the same day in 2010. These 2.67 million packages were delivered not only within 3 days to 5 days to customers in 31 provinces in the country but also under customized logistics service. This process brought huge pressure to the Yuantong Express Company. To complete the courier service, Yuantong Express Company cooperated with other FLSPs (e.g., SF Express and ZTO Express) by outsourcing some customer orders.

Under the MCLS environment, the LSI integrates different customer orders and allocates such orders to multiple FLSPs. In contrast to existing order allocation methods, the LSI needs to consider the influence of customer order decoupling points (CODPs). Each customer order has a unique CODP; therefore, when the LSI integrates multiple customer orders, the cost scale effect caused by large-scale services and the different CODPs of these orders should be considered. We also need to consider the minimum total cost of LSI and FLSP satisfaction in order allocation processes. Hence, a multiobjective decision-making problem exists. This problem involves addressing the diversity of customer orders, minimizing the total cost of the LSI, and considering the optimal satisfaction of FLSPs. This paper studies the order allocation problem (OAP) between LSI and multi-FLSPs, considers the characteristics of the MCLS by modeling and analysis, and explores the influence of related factors on the comprehensive performance of order allocation. Moreover, several management insights are provided.

This paper is organized as follows. Section 2 presents the literature review, where existing research on mass customization and order allocation are systematically summarized. Section 3 demonstrates the model building. An order allocation model of LSSC under the MCLS environment is established. Section 4 characterizes the model solution. A method for solving the multiobjective programming model is provided. Section 5 presents the numerical analysis. The influence of related factors on the comprehensive performance of order allocation is discussed in this section. Section 6 provides the main conclusions, management insights, and implications for LSI and FLSPs. Section 7 presents the limitations of the study and discusses suggestions for further research in this field.

\section{Literature Review}

This paper involves two main research areas: mass customization and order allocation. The literature review focuses on these two areas and elaborates their research progress and inadequacies.

2.1. Mass Customization. Studies on mass customization mainly include mass customization production and mass customization service. Mass customization production is primarily for manufacturing industry and mass customization service is mainly for service industry.

2.1.1. Mass Customization Production. Most mass customization production studies have focused on the supply chain of the manufacturing industry $[4,5]$. The main content of these studies is centered on the design of a delay system. Reference [6] proposed five kinds of postponement strategy: tags delay, packaging delay, assembly delay, manufacturing delay, and time delay. Thereafter, scholars studied the problem of choosing the appropriate postponement strategy in terms of the applicable conditions of time delay and cost delay in manufacturing [7]. Moreover, several scholars examined the influence of implementing postponement strategies on the cost of delay system $[8,9]$.

Studies on the decision-making problem of CODP have increased in recent years. In enterprise manufacturing activities, CODP is the transition point from make-to-stock to make-to-order [10]. In our paper, CODP indicates the procedure to start customization service. The positioning model of CODP has progressed from single CODP to multi-CODP [11, $12]$ and from static CODP to dynamic CODP [13, 14]. Given the increasing number of studies on supply chains, several scholars have investigated that the CODP problem undersupply chain environments and achieved fruitful research results. For example, reference [15] studied the influence of CODP selection on inventory costs when the lead time and universal module average holding cost are the same regardless of CODP position, which considers inventory and other costs in the model. Reference [16] examined the best CODP selection model around the supply chain environment.

2.1.2. Mass Customization Service. The increasing adoption of the service supply chain in recent years has attracted scholars in studying the CODP problem of the service industry under mass customization environments. These previous studies mainly examined how a single service enterprise positions the CODP in service processes while considering mass customization costs and ignoring inventory costs. Moreover, there is a special issue on service optimization and control in mathematical problems in engineering which includes a hot topic of mass customization service. There are also some scholars dedicating research perspective to specific industries, such as logistics services industry. References [17, 18] explored the scheduling model of LSSC in the context of MCLS.

2.2. Order Allocation on Supply Chain. To date, most OAPs are solved by using multiobjective linear programming or nonlinear programming methods, which spread around the produce supply chain. References $[19,20]$ studied the application of genetic algorithm for optimizing order allocation. Current studies on customer order allocation mainly consider the service level and minimizing procurement costs $[13,19$, 21]. And most studies have focused on the manufacturing industry supply chain. Several scholars have investigated the integrated multiobjective decision-making method, which considers both supplier selection and OAPs [22]. In addition to the solving method, several scholars have focused on the order allocation model, such as research on the order allocation model of supply chains with FLSP load cases [17, $18,23]$. 
The growth of LSSC has directed considerable research attention on its order allocation. Several studies have examined the OAP in two-echelon LSSC $[12,19]$. Reference [1] investigated an emergency order allocation model based on multiproviders in two-echelon LSSC. Considering the multiechelon nature of LSSC, references $[17,18]$ conducted a study on the order allocation of three-echelon LSSC.

The literature review indicates that the MCLS environment has been left unexamined even though scholars have focused on the OAP of LSSC. The MCLS needs to consider the cost advantages of mass service and customized special requirements; therefore, the order allocation in this case is clearly distinct from general cases. Furthermore, cost control is not the most important decision-making objective when we consider the customization requirements. Thus, this paper focuses on the OAP around the MCLS environment by modeling its characteristics and exploring the influence of related factors on the comprehensive performance of order allocation. Furthermore, several management insights are also provided.

\section{Model Building}

Section 3 introduces the model assumptions and variables. To maximize the satisfaction of FLSPs, minimize the total cost of the LSI, and maximize the customized degree of customers, we established a multiobjective order allocation model of LSSC that is constrained by meeting the demand, CODP, and order difference tolerance coefficient (Section 3.2).

3.1. Model Description. We considered a two-echelon LSSC, which consists of one LSI and many FLSPs. After receiving orders from multiple customers, the LSI analyzes the customized and universal service requirements of these customer orders and allocates them to more than one FLSP. Every logistic service for customer orders comprises multiple service processes. Each process needs one kind of service that can be provided by many cooperative FLSPs. The service capability of each FLSP is possibly different. We assumed that $\left[a_{i j k}, b_{i j k}\right]$ denotes the service ability interval provided by FLSP $i$ th for customer $j$ th in the procedure $k$ th; $x_{i j k}$ stands for the $j$ th customer's order assigned to the $i$ th FLSP in the $k$ th procedure.

Table 1 shows the notations of the model. The other assumptions of the model are as follows.

(1) Each FLSP $i(i=1,2, \ldots, n)$ can provide mass service and customization service for the LSI. The total service procedures of customer $j$ are $L_{j}(j=$ $1,2, \ldots, M)$, and the order demand is $D_{j}$.

(2) $K_{j}$ represents the procedure to start the customization service of the $j$ th customer; this service is not necessarily the same for all customers. The LSI needs to consider the $K_{j}$ of all customers and set a common CODP, which is signified by $K^{\prime}$ for all customers. $K^{\prime}$ is mass service, and $K^{\prime}$ is customization service. $K^{\prime}$ should be set before $K_{0}\left(K_{0}=\min \left\{K_{1}, K_{2}, \ldots, K_{M}\right\}\right)$ because the CODP must be set before all $K_{j}$. Given the characteristics of the MCLS, Procedure 1 must be mass service; hence, $2 \leq K^{\prime} \leq K_{0}$ ).

(3) Given the importance of different customizations for each customer, the weight of the $j$ th customer is $\beta_{j}$ $\left(\sum_{j=1}^{M} \beta_{j}=1\right)$.

(4) Customer orders are assigned to FLSPs through the LSI. FLSPs will accomplish the order assigned by the LSI. No game exists between LSI and FLSPs.

3.2. Model Building. Previous order allocation models are mostly based on the costs and orders service level [13, 16, 24]. While conducting the order allocation of the LSSC under the MCLS environment, the LSI is required to consider multiobjectives, such as the total cost of the LSI, the total satisfaction of FLSPs, and the satisfaction of customized demand. To maximize the satisfaction of FLSPs, minimize the total cost of the LSI, and maximize the customization degree for customer demand, this paper establishes an order allocation model of LSSC that is constrained by meeting the demand, CODP, and order difference tolerance coefficient. The greatest difference between the previous model and ours is that we considered the impact of changing CODP on order allocation result, so that it can reflects the order allocation characteristics on MCLS better. The specific modeling procedure is described in the following sections. Sections 3.2.1 to 3.2.4 discuss the building processes of several aspects, namely, the objective function of FLSP satisfaction, LSI total cost, the objective function of customized degree for customer demand, and the three constraints, respectively.

3.2.1. Maximizing the Satisfaction of FLSPs. Maximizing the satisfaction of FLSPs is considered the first process by the LSI in order allocation. Based on the satisfaction function of reference [1], the satisfaction of the $i$ th FLSP for the $j$ th customer in the $k$ th procedure is as follows:

$$
\rho_{i j k}= \begin{cases}\frac{b_{i j k}}{x_{i j k}}, & x_{i j k}>b_{i j k}, \\ \rho_{i j k}^{0}+\left(1-\rho_{i j k}^{0}\right) * \frac{x_{i j k}-a_{i j k}}{b_{i j k}-a_{i j k}}, & a_{i j k} \leq x_{i j k} \leq b_{i j k} \\ \frac{x_{i j k}}{a_{i j k}} * \rho_{i j k}^{0}, & 0 \leq x \leq a_{i j k},\end{cases}
$$

where $\rho_{i j k}^{0}$ is the initial satisfaction of the $i$ th FLSP in the $k$ th procedure when the order value is equal to the minimum service capacity (1). Each FLSP has different service capacity intervals while conducting mass service and customization service, which can be expressed as $k \leq K^{\prime},\left[a_{i j k}, b_{i j k}\right]=$ $\left[a_{i j k 1}, b_{i j k 1}\right] ; k>K^{\prime},\left[a_{i j k}, b_{i j k}\right]=\left[a_{i j k 2}, b_{i j k 2}\right]$. In the same manner, each FLSP has different initial satisfaction on mass service and customization service. This initial satisfaction can be expressed as $k \leq K^{\prime},\left[a_{i j k}, b_{i j k}\right]=\left[a_{i j k 1}, b_{i j k 1}\right] ; k>K^{\prime}$, $\left[a_{i j k}, b_{i j k}\right]=\left[a_{i j k 2}, b_{i j k 2}\right]$. When $0 \leq x \leq a_{i j k}$, the satisfaction of the FLSP increases with increasing order value. Similarly, when $a_{i j k} \leq x_{i j k} \leq b_{i j k}$, the satisfaction of the FLSP increases 
TABLE 1: Model notations.

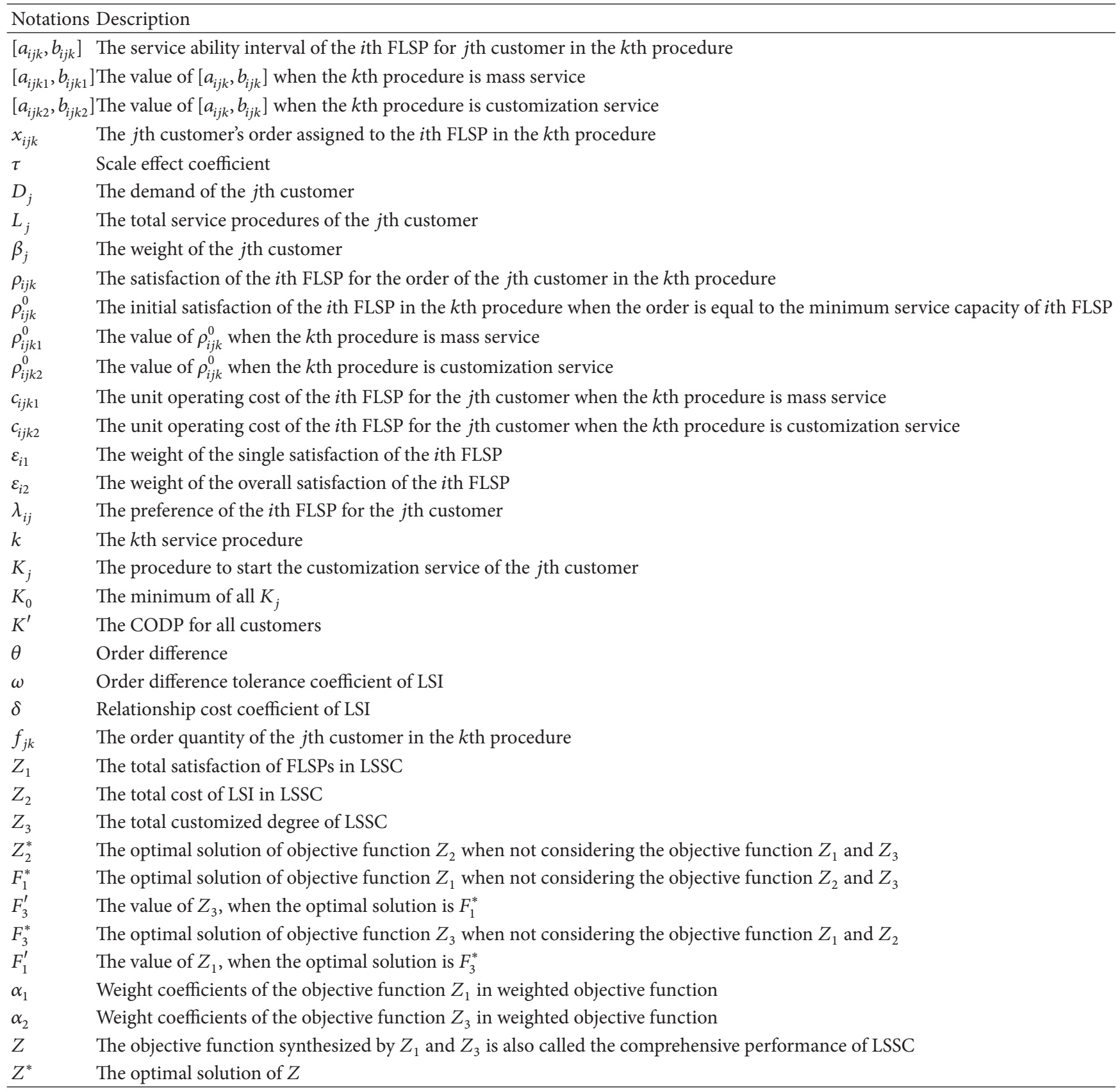

with increasing order value (the satisfaction maximum is one). However, when $x_{i j k} \geq b_{i j k}$, the satisfaction of the FLSP decreases with increasing order value because the order exceeds the upper limit of the service capacity.

Given that each FLSP has different preferences for each customer, satisfaction comprises single satisfaction and overall satisfaction. The weight of the single satisfaction of the $i$ th FLSP is $\varepsilon_{i 1}$, and the weight of the overall satisfaction of the $i$ th FLSP is $\varepsilon_{i 2}\left(\varepsilon_{i 1}+\varepsilon_{i 2}=1\right)$.

(1) Single satisfaction: the satisfaction of the FLSP for the order allocation result of one customer. Assuming that the preference of the $i$ th FLSP for the $j$ th customer is $\lambda_{i j}, \sum_{j=1}^{M} \lambda_{i j}$ is equal to one, thus, the single satisfaction of the $i$ th FLSP is $\varepsilon_{i 1}\left(\sum_{j=1}^{M} \lambda_{i j}\left(1 / L_{j}\right) \sum_{k=1}^{L_{j}} \rho_{i j k}\right)$.

(2) Overall satisfaction: the satisfaction of the FLSP for the order allocation result of all customers. If the FLSP can service two customers, the FLSP expects that the satisfaction for both customers is high. Usually, we use the average satisfaction of multiple customers to represent the overall satisfaction. Thus, the overall satisfaction of the $i$ th FLSP is $\varepsilon_{i 2}\left((1 / M) \sum_{j=1}^{M}\left(1 / L_{j}\right) \sum_{k=1}^{L_{j}} \rho_{i j k}\right)$. 
The total satisfaction of $i$ th FLSP is $\varepsilon_{i 1}\left(\sum_{j=1}^{M} \lambda_{i j}(1 /\right.$ $\left.\left.L_{j}\right) \sum_{k=1}^{L_{j}} \rho_{i j k}\right)+\varepsilon_{i 2}\left((1 / M) \sum_{j=1}^{M}\left(1 / L_{j}\right) \sum_{k=1}^{L_{j}} \rho_{i j k}\right)$.

Therefore, the objective function of maximizing the satisfaction of FLSPs is expressed as follows:

$$
\begin{aligned}
\max Z_{1}=\frac{1}{n} \sum_{i=1}^{n}( & \varepsilon_{i 1}\left(\sum_{j=1}^{M} \lambda_{i j} \frac{1}{L_{j}} \sum_{k=1}^{L_{j}} \rho_{i j k}\right) \\
& \left.+\varepsilon_{i 2}\left(\frac{1}{M} \sum_{j=1}^{M} \frac{1}{L_{j}} \sum_{k=1}^{L_{j}} \rho_{i j k}\right)\right) .
\end{aligned}
$$

3.2.2. Minimizing the Total Cost of the LSI. In the order allocation process, the LSI also considers minimizing the cost. The total cost of the LSI is related not only to the number of orders assigned but also to the position of the CODP. When CODP approaches the customer, the quantity of procedures and order of mass services increase; the order of mass service is also obvious. Therefore, the scale effect is more noticeable.

The total cost of the LSI consists of two parts, namely, mass service cost and customization service cost. The unit operating cost of the $i$ th FLSP for the $j$ th customer is $c_{i j k 1}$ when the $k$ th procedure is mass service (3). The unit operating cost of the $i$ th FLSP for the $j$ th customer is $c_{i j k 2}$ when the $k$ th procedure is customization service (4). Consider

$$
\begin{gathered}
c_{i j k 1}=A_{i k}-B_{i k} x_{i j k}, \\
c_{i j k 2}=C_{i},
\end{gathered}
$$

where $c_{i j k 1}$ displays a scale effect, which decreases with the increasing of $x_{i j k}(3)$. A larger $x_{i j k}$ corresponds to a smaller $c_{i j k 1}$. However, because of the characteristics of customization, $c_{i j k 2}$ does not change with the variation of $x_{i j k}$.

When the procedure of mass service is $K^{\prime}$ because of the existence of the scale effect, an increase in $K^{\prime}$ corresponds to a smaller $c_{i j k 1}$. Hence, we introduce the scale effect coefficient $\tau$, which is related to the number of procedures. The cost of the $i$ th FLSP for the $j$ th customer in all procedures is expressed as follows:

$$
\begin{array}{r}
\sum_{k=1}^{K^{\prime}} c_{i j k 1} * x_{i j k}-\tau K^{\prime} \sum_{k=1}^{K^{\prime}} c_{i j k 1} * x_{i j k} \\
=\left(1-\tau K^{\prime}\right) \sum_{k=1}^{K^{\prime}} c_{i j k 1} * x_{i j k} .
\end{array}
$$

The cost of all FLSPs is summarized. Thereafter, the objective function of minimizing the total cost of the LSI is obtained:

$$
\begin{aligned}
& \min Z_{2} \\
& \quad=\sum_{i=1}^{n} \sum_{j=1}^{M}\left(\left(1-\tau K^{\prime}\right) \sum_{k=1}^{K^{\prime}} c_{i j k 1} * x_{i j k}+\sum_{k=K^{\prime}+1}^{L_{j}} c_{i j k 2} * x_{i j k}\right) .
\end{aligned}
$$

3.2.3. Maximizing the Customized Degree for Customer Demand. Under the MCLS environment, each customer will intend to maximize their own customized degree. Therefore, the customized degree for customer demand is one of the most important objectives. However, given that the customized degree for customer demand will affect the total cost of the LSI, the former cannot be too high. Mass customization involves reducing total cost as much as possible and maximizing the customized demand (i.e., increase the cost of customization services). Thus, we multiply the ratio of the customization service cost and total cost by the weight to represent the customized degree of each customer. We then summarize the customized degree of each customer to obtain the customized degree of all customers:

$$
\begin{aligned}
& \max Z_{3}=\sum_{j=1}^{M} \beta_{j}\left(\left(\sum_{i=1}^{n} \sum_{k=K^{\prime}+1}^{L_{j}} c_{i j k 2} * x_{i j k}\right)\right. \\
& \times\left(\sum _ { i = 1 } ^ { n } \left(\left(1-\tau K^{\prime}\right) \sum_{k=1}^{K^{\prime}} c_{i j k 1} * x_{i j k}\right.\right. \\
&\left.\left.\left.+\sum_{k=K^{\prime}+1}^{L_{j}} c_{i j k 2} * x_{i j k}\right)\right)^{-1}\right) .
\end{aligned}
$$

3.2.4. Order Allocation Constraints. In the order allocation process, the LSI also needs to meet several constraints. First, the total order quantity of all FLSPs should be equal to the customer demand in the $k$ th procedure. Second, the $K^{\prime}$ (CODP) should be between the second procedure and the $K_{0}$ procedure $\left(K_{0}=\min \left\{K_{1}, K_{2}, \ldots, K_{M}\right\}\right)$. Third, given that the service procedures of each customer and the procedures to start the customization service are different, the LSI needs to consider the order difference $\theta$ of customers while serving multiple customers. To conduct mass customization service, the order difference cannot be extremely high. That is, $\theta$ cannot exceed the upper limit $\omega$. Finally, $x_{i j k}$ must be nonnegative. The four constraints can be expressed as (8), (9), (10), and (11):

$$
\begin{gathered}
\sum_{i=1}^{n} \sum_{j=1}^{M} x_{i j k}=\sum_{j=1}^{M} f_{j k}, \\
2 \leq K^{\prime} \leq K_{0}, \\
\theta=\frac{1}{M} \sum_{j=1}^{M} \frac{K_{j}-K^{\prime}}{K_{j}} \leq \omega \\
x_{i j k} \geq 0, \quad i=1,2, \ldots, n ; j=1,2, \ldots, M ; k=1,2, \ldots, L_{j} .
\end{gathered}
$$

As shown in (10), $\theta$ can be expressed as (12):

$$
\theta=\frac{1}{M} \sum_{j=1}^{M} \frac{K_{j}-K^{\prime}}{K_{j}} .
$$


Equation (12) shows that $\theta$ is related to $K_{j}$ and $K^{\prime}$. If $K_{j}$ is equal to $K^{\prime}, \theta$ is zero. A larger gap between $K_{j}$ and $K^{\prime}$ corresponds to a higher $\theta$ value.

Combining the three objective functions given in Sections 3.2.1 to 3.2.3, we establish a multiobjective order allocation model under the MCLS environment ((13) to (19)). Consider

$$
\begin{aligned}
& \max Z_{1}=\frac{1}{n} \sum_{i=1}^{n}\left(\varepsilon_{i 1}\left(\sum_{j=1}^{M} \lambda_{i j} \frac{1}{L_{j}} \sum_{k=1}^{L_{j}} \rho_{i j k}\right)\right. \\
& \left.+\varepsilon_{i 2}\left(\frac{1}{M} \sum_{j=1}^{M} \frac{1}{L_{j}} \sum_{k=1}^{L_{j}} \rho_{i j k}\right)\right), \\
& \min Z_{2}=\sum_{i=1}^{n} \sum_{j=1}^{M}\left(\left(1-\tau K^{\prime}\right) \sum_{k=1}^{K^{\prime}} c_{i j k 1} * x_{i j k}\right. \\
& \left.+\sum_{k=K^{\prime}+1}^{L_{j}} c_{i j k 2} * x_{i j k}\right) \\
& \max Z_{3}=\sum_{j=1}^{M} \beta_{j}\left(\left(\sum_{i=1}^{n} \sum_{k=K^{\prime}+1}^{L_{j}} c_{i j k 2} * x_{i j k}\right)\right. \\
& \times\left(\sum _ { i = 1 } ^ { n } \left(\left(1-\tau K^{\prime}\right) \sum_{k=1}^{K^{\prime}} c_{i j k 1} * x_{i j k}\right.\right. \\
& \left.\left.\left.+\sum_{k=K^{\prime}+1}^{L_{j}} c_{i j k 2} * x_{i j k}\right)\right)^{-1}\right) \\
& \text { s.t } \sum_{i=1}^{n} \sum_{j=1}^{M} x_{i j k}=\sum_{j=1}^{M} f_{j k} \\
& 2 \leq K^{\prime} \leq K_{0}, \\
& \theta=\frac{1}{M} \sum_{j=1}^{M} \frac{K_{j}-K^{\prime}}{K_{j}} \leq \omega, \\
& x_{i j k} \geq 0, \quad i=1,2, \ldots, n ; j=1,2, \ldots, M ; k=1,2, \ldots, L_{j} .
\end{aligned}
$$

In the objective functions, (13) maximizes the satisfaction of FLSPs; (14) minimizes the total cost of the LSI; (15) maximizes the customized degree for customer demand.

For the constraints, (16) implies that the service capacity supply is equal to the order demand in each procedure; (17) means that $K^{\prime}$ (CODP) should be between the second procedure and $K_{0}$ procedure. Equation (18) indicates that the order difference should be less than the order difference tolerance coefficient. Equation (19) denotes that the order assigned to each FLSP must be nonnegative.

\section{Model Solution}

The model is a multiobjective programming problem with three objectives and three constraints. Multiobjective programming problems have numerous mature solutions, such as the evaluation function method including linear weighting method, reference target method, maximin method [9], goal programming method [25], delaminating sequence method [26], and subordinate function method [27]. For the specific issues, it is necessary to choose an appropriate solution method to solve the practical problems. Given that conflicts and incommensurability between goals exists, finding an absolute optimal solution is difficult. Therefore, a compromise between the various objectives is commonly performed to obtain the Pareto-optimal solution for decision makers. Specifically, two approaches can be used to solve multiobjective programming problem. One is to balance between objectives, assign weight to each of the objective functions and switch the multiobjective functions to a single objective function. The other method is to reduce the number of objective functions and transform the reduced objective functions into constraints. However, on MCLS, the LSI should not only consider the total cost target but also the satisfaction target and the customized degree target. Generally, supply chain management emphasizes the strategic partnership. In order to maintain long-term cooperation with FLSPs and customers, in order allocation, the LSI should keep the total cost within a specific range instead of merely seeking for the minimum. Maximizing the satisfaction and the customized degree should be the target. As a result, we transform the total cost objective into a constraint to reduce the number of objective functions and transform the target of satisfaction customized degree into a single objective, after which the model is solved.

Based on the previous solving methods, in order allocation, considering these actual situations, we introduce a parameter called the relationship cost coefficient $\delta$ into our model. This parameter is used to represent the increasing cost limit of the LSI to enhance the cooperation and satisfaction of FLSPs and customers. Hence, $Z_{2}$ can become a constraint. Thereafter, we choose a linear weighting method, which is the most typical method, to transform the multiobjective $Z_{1}, Z_{3}$ into a single objective $Z$ and solve the model. The specific steps in solving the model are as follows.

Step 1. The consideration of the objective functions $Z_{1}, Z_{3}$ is set aside to consider the case of objective function $Z_{2}$. Thereafter, the relationship cost coefficient $\delta$ is introduced. The objective can then be translated into a constraint:

$$
Z_{2} \leq(1+\delta) Z_{2}^{*}
$$

This approach denotes that the LSI can minimize and maintain the total cost within a certain range. $\delta=0.2$ means that the LSI can exist with a total cost less than 1.2 times of $Z_{2}^{*}$ to increase the satisfaction and customized degree. The LSI considers this input to be conducive in the completion of orders. 
Step 2. The model has $Z_{1}$ and $Z_{3}$. The linear weighing method is used to transform the objective $Z_{1}$ and $Z_{3}$ into a new objective function $\max Z=\alpha_{1} Z_{1}+\alpha_{2} Z_{3}\left(\alpha_{1}+\alpha_{2}=1\right)$. Determining the weight $\left(\alpha_{1}, \alpha_{2}\right)$ is the main problem of this approach. $\alpha_{1}, \alpha_{2}$ can be determined by the following equation:

$$
\begin{aligned}
& \alpha_{1}=\frac{F_{3}^{*}-F_{3}^{\prime}}{F_{1}^{*}-F_{1}^{\prime}+F_{3}^{*}-F_{3}^{\prime}}, \\
& \alpha_{2}=\frac{F_{1}^{*}-F_{1}^{\prime}}{F_{1}^{*}-F_{1}^{\prime}+F_{3}^{*}-F_{3}^{\prime}} .
\end{aligned}
$$

Step 3. After determining $\alpha_{1}$ and $\alpha_{2}$, the model is transformed into a single-objective planning model:

$$
\begin{gathered}
\max Z=\alpha_{1} Z_{1}+\alpha_{2} Z_{3}, \\
\text { s.t } Z_{2} \leq(1+\delta) Z_{2}^{*}, \\
\sum_{i=1}^{n} \sum_{j=1}^{M} x_{i j k}=\sum_{j=1}^{M} f_{j k}, \\
2 \leq K^{\prime} \leq K_{0}, \\
\theta=\frac{1}{M} \sum_{j=1}^{M} \frac{K_{j}-K^{\prime}}{K_{j}} \leq \omega, \\
x_{i j k} \geq 0, \quad i=1,2, \ldots, n ; j=1,2, \ldots, M ; k=1,2, \ldots, L_{j} .
\end{gathered}
$$

In solving the objective function $Z$, the $x_{i j k}$ obtained is the optimal solution $Z^{*}$. $Z$ reflects the comprehensive performance of the LSSC. A bigger $Z$ corresponds to better comprehensive performance.

\section{Numerical Analysis}

This section illustrates the validity of the model by numerical analysis, explores the influence of related factors on time scheduling results, and provides several management insights. First, we use the Lingo 12 software to implement the numerical analysis. The results are shown in Section 5.1. From the perspective of LSI order management decision, we choose and study the influence of following factors $(\tau, \omega, \delta)$ on order allocation decision (Section 5.2 to Section 5.5). $\tau$ is an important factor to reflect the scale effect on MCLS. $\omega$ is also an important factor to reflect the influence of order difference on LSI's decision making. $\delta$ indicates the cost volatility with which the LSI can live. We will study the influence of the three $(\tau, \omega, \delta)$ on order allocation separately.

5.1. Model Solution. Figures 1 and 2 show that each customer $(\mathrm{A}, \mathrm{B}$, and $\mathrm{C})$ has an order and needs the LSI Q to provide transportation services. Q assigns the three orders to the FLSPs (a, b, c, d, and e). The demand of each customer is 60,100 , and 80 . The number of service procedures of each customer is 8, 7, and 7. $K_{1}=6, K_{2}=5, K_{3}=5, K_{0}=$ $\min \left(K_{1}, K_{2}, K_{3}\right)=5, \tau=0.05, \omega=0.4$, and $\delta=20 \%$. The values of other parameters are shown in Tables 2 and 3.
TABLE 2: Parameter data (1).

\begin{tabular}{lcc}
\hline$\left[a_{i j k}, b_{i j k}\right]$ & {$\left[a_{i j k 1}, b_{i j k 1}\right]$} & {$\left[a_{i j k 2}, b_{i j k 2}\right]$} \\
\hline$i=1$ & {$[40,80]$} & {$[20,40]$} \\
$i=2$ & {$[30,70]$} & {$[20,35]$} \\
$i=3$ & {$[35,90]$} & {$[25,40]$} \\
$i=4$ & {$[30,60]$} & {$[25,50]$} \\
$i=5$ & {$[30,80]$} & {$[10,40]$} \\
\hline$c_{i j k}$ & $c_{i j k 1}$ & $c_{i j k 2}$ \\
\hline$i=1$ & $10-0.02 x_{i j k}$ & 15 \\
$i=2$ & $11-0.02 x_{i j k}$ & 18 \\
$i=3$ & $9-0.02 x_{i j k}$ & 16 \\
$i=4$ & $12-0.02 x_{i j k}$ & 20 \\
$i=5$ & $14-0.02 x_{i j k}$ & 22 \\
\hline$\rho_{i j k}$ & $\rho_{i j k 1}$ & $\rho_{i j k 2}$ \\
\hline$i=1$ & 0.2 & 0.3 \\
$i=2$ & 0.35 & 0.35 \\
$i=3$ & 0.15 & 0.3 \\
$i=4$ & 0.3 & 0.2 \\
$i=5$ & 0.25 & 0.3 \\
\hline$\varepsilon_{i}$ & $\varepsilon_{i 1}$ & $\varepsilon_{i 2}$ \\
\hline$i=1$ & 0.6 & 0.4 \\
$i=2$ & 0.5 & 0.5 \\
$i=3$ & 0.7 & 0.3 \\
$i=4$ & 0.4 & 0.6 \\
$i=5$ & 0.35 & 0.65 \\
\hline & &
\end{tabular}

Table 3: Parameter data (3).

\begin{tabular}{lccc}
\hline$\lambda_{i j}$ & $j=1$ & $j=2$ & $j=3$ \\
\hline$i=1$ & 0.3 & 0.3 & 0.4 \\
$i=2$ & 0.2 & 0.4 & 0.4 \\
$i=3$ & 0.35 & 0.35 & 0.3 \\
$i=4$ & 0.25 & 0.35 & 0.4 \\
$i=5$ & 0.3 & 0.4 & 0.3 \\
$\beta_{j}$ & 0.3 & 0.4 & 0.3 \\
$D_{j}$ & 60 & 100 & 80 \\
$K_{j}$ & 6 & 5 & 5 \\
$L_{j}$ & 8 & 7 & 7 \\
\hline
\end{tabular}

By using the solution method in Section 4, Tables 4 and 5 show the result and performance of the order allocation, respectively.

5.2. Influence of Scale Effect Coefficient $\tau$ on Order Allocation. To analyze the influence of $\tau$ on the related factors of order allocation $\left(Z_{2}, \operatorname{CODP}, Z_{3}, Z\right)$, we make $\tau$ equal to $0,0.025$, $0.05,0.075,0.1,0.125$, and 0.15 . The data is shown in Table 6 . Figures 3 to 6 are plotted with the data from Table 6 .

Figure 3 shows that $\tau$ has significant influence on the total cost of LSI $Z_{2}$. A greater $\tau$ corresponds to a smaller $Z_{2}$. The scale effect of the cost is more obvious with increasing $\tau$; thus, the total cost decreases. 


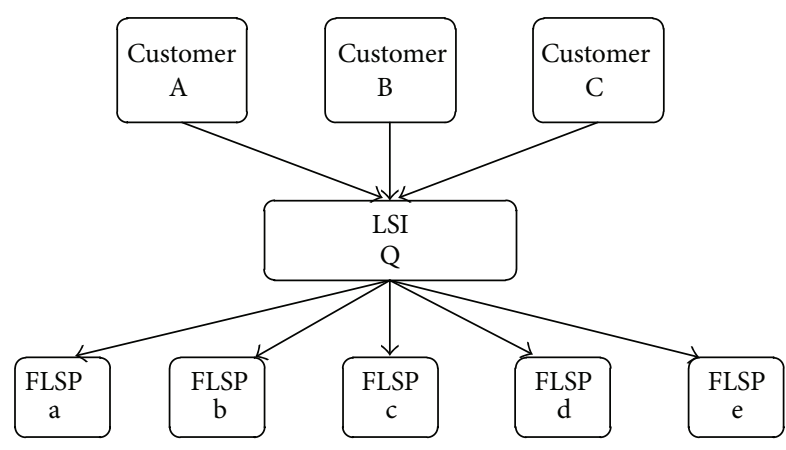

FIgURE 1: Structure of the LSSC.

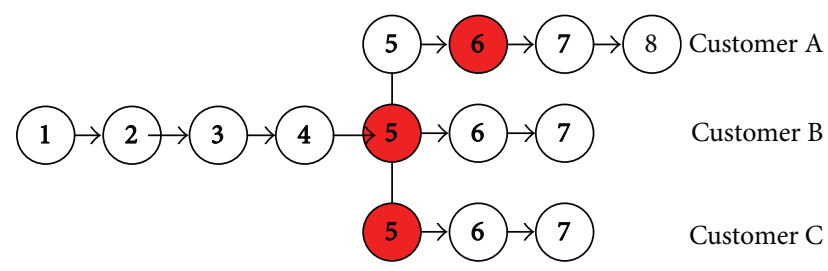

Note: The arrows indicate the flow of the order allocation.

FIgURE 2: Logistics service procedure of customer A, B, and C. Note: The red circle denotes the procedure that starts the customization service of each customer.

TABLE 4: Order allocation results.

\begin{tabular}{|c|c|c|c|c|c|c|c|}
\hline Procedure & & $1-5$ & & & $6-7$ & & 8 \\
\hline $\begin{array}{l}\text { Customer } \\
\text { Order value } \\
\text { FLSP }\end{array}$ & A & B & $\mathrm{C}$ & A & B & $\mathrm{C}$ & A \\
\hline a & 0 & 4.31 & 0 & 31.59 & 18.20 & 37.79 & 31.59 \\
\hline $\mathrm{b}$ & 0 & 6.33 & 0 & 6.14 & 37.86 & 0.53 & 6.14 \\
\hline c & 60 & 4.99 & 80 & 4.63 & 40 & 37.82 & 4.63 \\
\hline d & 0 & 4.93 & 0 & 6.41 & 0.35 & 0 & 6.41 \\
\hline $\mathrm{e}$ & 0 & 79.44 & 0 & 11.23 & 3.60 & 3.86 & 11.23 \\
\hline
\end{tabular}

TABLE 5: Order allocation performance.

\begin{tabular}{lc}
\hline Total cost of LSSC & 17472.020 \\
CODP & 5 \\
Customized degree & 0.522 \\
$Z$ & 0.391 \\
\hline
\end{tabular}

TABLE 6: Influence of $\tau$ on order allocation.

\begin{tabular}{lcccc}
\hline$\tau$ & $Z_{2}$ & $Z_{3}$ & CODP & $Z$ \\
\hline 0 & 20280 & 0.596 & 4 & 0.403 \\
0.025 & 18960.000 & 0.524 & 5 & 0.388 \\
0.05 & 17472.020 & 0.522 & 5 & 0.391 \\
0.075 & 16320.000 & 0.580 & 5 & 0.417 \\
0.1 & 15000.000 & 0.638 & 5 & 0.469 \\
0.125 & 13680.000 & 0.646 & 5 & 0.472 \\
0.15 & 12360.000 & 0.783 & 5 & 0.582 \\
\hline
\end{tabular}

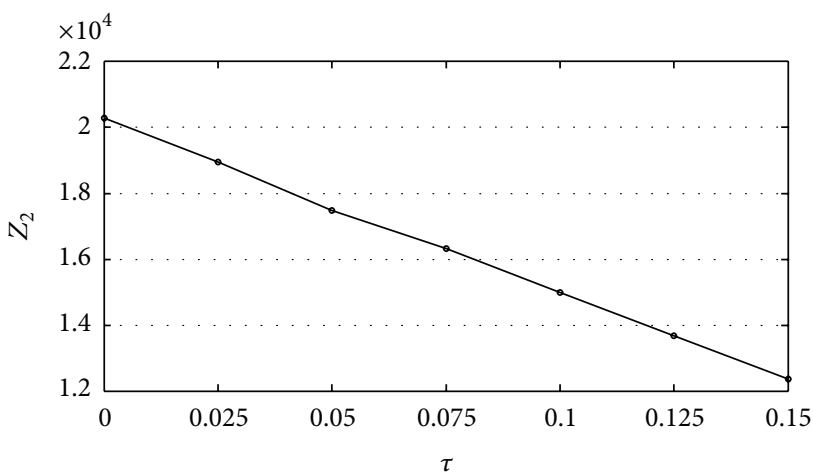

FIgURE 3: Influence of $\tau$ on $Z_{2}$ (total cost of LSI).

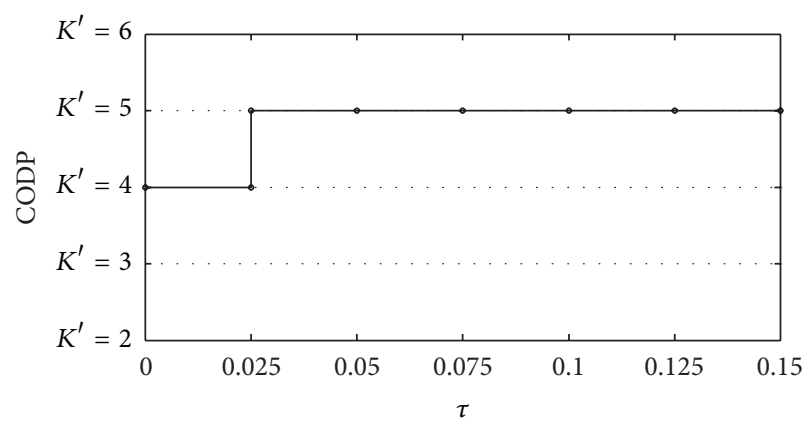

FIGURE 4: Influence of $\tau$ on CODP.

Figure 4 shows that $\tau$ has a certain influence on CODP. If $\tau=0$, the scale effect is nonexistent and the CODP is in the fourth procedure. With $\tau \geq 0.025$, the CODP changes to the fifth procedure because the scale effect of cost is more obvious with increasing $\tau$. Therefore, the LSI will delay the CODP to acquire a considerable scale effect.

If $\tau<0.05$, the customized degree $Z_{3}$ decreases with increasing $\tau$, which is contrary to $\tau \geq 0.05$ (Figure 5). $Z_{3}$ initially decreases and then increases. This observation differs from the observation of previous studies that an increasing $\tau$ corresponds to a more obvious scale effect and smaller cost of mass service. Furthermore, previous studies show that the customized degree is equal to the ratio of the customization service cost and total cost (mass service cost plus customization service cost). Therefore, the customized degree should always increase.

Our results differ from those of previous studies that did not include the CODP. The LSI will delay the CODP to acquire the scale effect, which leads to a significant increase in mass service cost and a decrease in customized degree (Figure 4). Furthermore, the CODP becomes stable when $\tau$ increases to a certain value. A greater $\tau$ corresponds to a more obvious scale effect. The increasing extent of the mass service cost becomes smaller and the customized degree becomes larger. The mass service cost decreases and the CODP moves backward with increasing $\tau$. The customized degree initially decreases and then increases. 


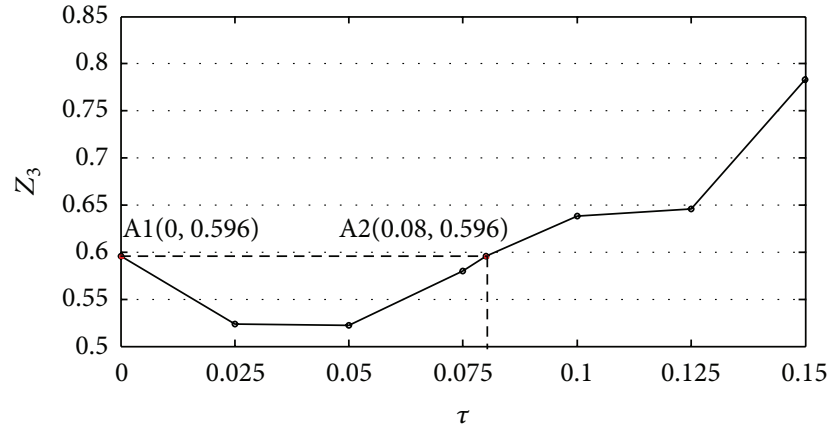

FIGURE 5: Influence of $\tau$ on $Z_{3}$ (customized degree).

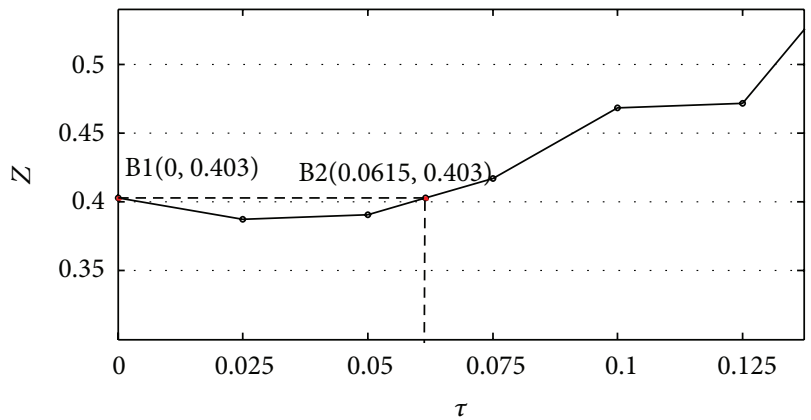

FIGURE 6: Influence of $\tau$ on $Z$ (comprehensive performance of LSSC).

If $\tau \prec 0.025, Z$ decreases with increasing $\tau$, which is contrary to $\tau \geq 0.025$ (Figure 6). The comprehensive performance of LSSC initially decreases and then increases.

Further analysis shows that when $Z$ is greater than 0.403 $(\tau=0.0615), Z$ increases with increasing $\tau$; thus, the LSI prefers the FLSP with a bigger $\tau$. When $Z$ is less than 0.403 $(\tau=0.0615)$, two $\tau$ 's equal one performance. The LSI still prefers the FLSP with a bigger $\tau$ because a bigger $\tau$ leads to smaller total costs.

5.3. Influence of Order Difference Tolerance Coefficient $\omega$ on Order Allocation. To analyze the influence of $\omega$ on the related factors of order allocation $\left(Z_{2}, \operatorname{CODP}, Z_{3}, Z\right)$, we equate $\omega$ to $0.4,0.45,0.5,0.55,0.6,0.65,0.7,0.8,0.9$, and 1 . The data is shown in Table 7 . Figures 7 to 10 are plotted by using the data from Table 7.

The order difference tolerance coefficient $\omega$ has a certain influence on the total cost of the LSI (Figure 7). The total cost of the LSI increases with increasing $\omega$. The order difference also increases with increasing $\omega$. The CODP should be set before $K_{0}=\min \left\{K_{1}, K_{2}, \ldots, K_{M}\right\}$. The CODP may move forward, thus increasing the procedure of customization service and total cost. Therefore, the LSI should choose the customer with low order difference and maintain the CODP in the same point to reduce total cost.

When $\omega$ is greater than 0.65 , the total cost is stable at 17,640 (Figure 7 ). Increasing $\omega$ with no limitations is unnecessary because of the upper limit $(\omega=0.65$ in numerical
TABLE 7: Influence of $\omega$ on order allocation.

\begin{tabular}{lcccc}
\hline$\omega$ & $Z_{2}$ & $Z_{3}$ & CODP & $Z$ \\
\hline 0.4 & 17472.020 & 0.522 & 5 & 0.391 \\
0.45 & 17472.020 & 0.522 & 5 & 0.391 \\
0.5 & 17499.530 & 0.613 & 5 & 0.471 \\
0.55 & 17499.530 & 0.613 & 5 & 0.471 \\
0.6 & 17499.530 & 0.613 & 5 & 0.471 \\
0.65 & 17640.000 & 0.681 & 4 & 0.561 \\
0.7 & 17640.000 & 0.681 & 4 & 0.561 \\
0.8 & 17640.000 & 0.681 & 4 & 0.561 \\
0.9 & 17640.000 & 0.681 & 4 & 0.561 \\
1 & 17640.000 & 0.681 & 4 & 0.561 \\
\hline
\end{tabular}

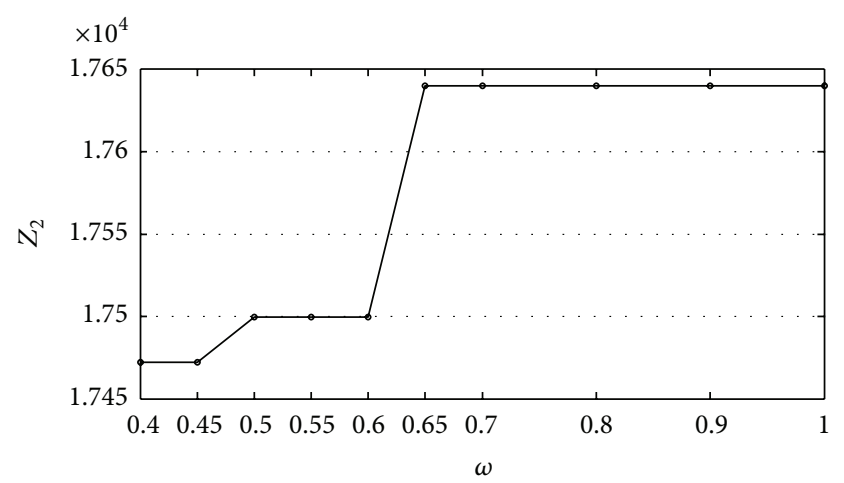

FIgURE 7: Influence of $\omega$ on $Z_{2}$ (total cost of LSI).

analysis). Consequently, the LSI should set a reasonable upper limit for $\omega$ in the MCLS.

When $\omega$ is less than 0.65 , the CODP is in the fifth procedure; when $\omega$ is larger than 0.65 , the CODP is in the fourth procedure (Figure 8 ). These findings show that $\omega$ has a certain influence on CODP. A larger $\omega$ corresponds to a larger $\mathrm{CODP}$ range. The CODP moves forward with increasing $\omega$ to a certain value.

Figure 9 demonstrates that $\omega$ affects $Z_{3} . Z_{3}$ increases with increasing $\omega$. The CODP moves to the second procedure, thus increasing the procedure of customization service. Consequently, the customized degree will also increase. When $\omega$ is greater than 0.65 , increasing $\omega$ with no limitation is unnecessary because of the upper limit. Thus, the LSI should set a reasonable upper limit for $\omega$ in the MCLS.

Figure 10 indicates that $Z$ increases steadily with increasing $\omega$ and becomes stable at 0.561. The comprehensive performance of LSSC shows a step growth instead of a linear growth with increasing $\omega$. This observation is attributed to the forward movement of the CODP to the second procedure. Variables $\omega$ and $Z$ have ranges; however, the CODP cannot move forward indefinitely because it must move after the second procedure, which determines the maximum value of $\omega ; \omega$ is not a constraint if it is greater than the maximum value.

5.4. Influence of Relationship Cost Coefficient $\delta$ on Order Allocation. To analyze the influence of $\delta$ on the related factors of order allocation $\left(Z_{2}, \operatorname{CODP}, Z_{3}, Z\right)$, we equated $\delta$ to 0.15 , 


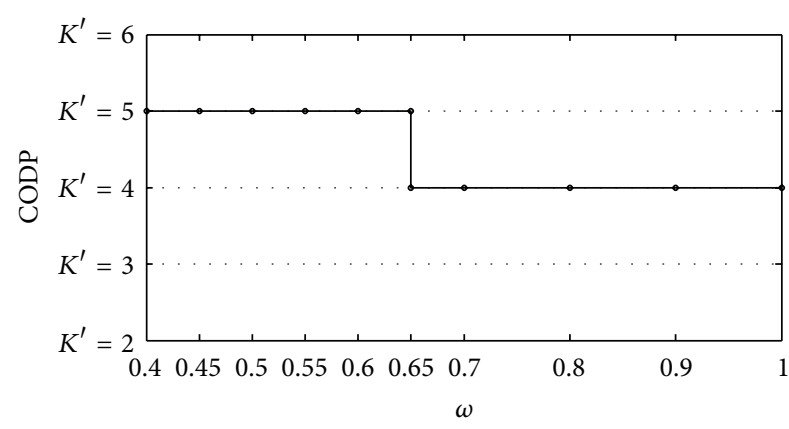

Figure 8: Influence of $\omega$ on CODP.

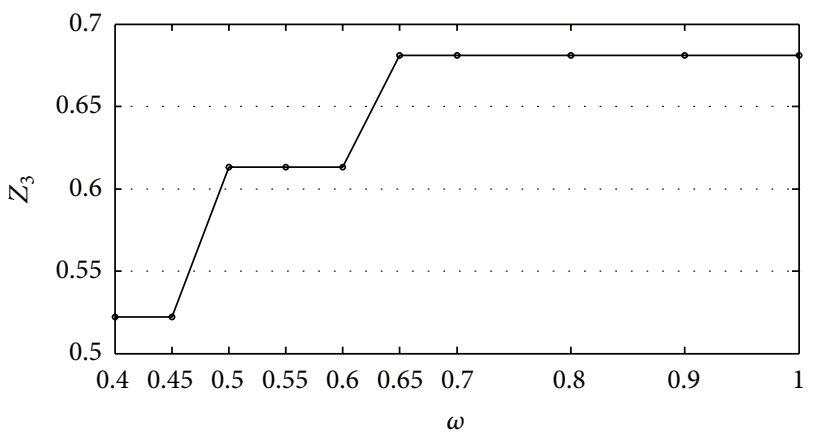

FIgURE 9: Influence of $\omega$ on $Z_{3}$ (customized degree).

TABLE 8: Influence of $\delta$ on order allocation.

\begin{tabular}{lcccc}
\hline$\delta$ & $Z_{2}$ & $Z_{3}$ & CODP & $Z$ \\
\hline 0.15 & 15400.000 & 0.575 & 5 & 0.421 \\
0.2 & 17472.020 & 0.522 & 5 & 0.391 \\
0.25 & 17990.84 & 0.570 & 5 & 0.413 \\
0.3 & 18887.720 & 0.652 & 4 & 0.497 \\
0.35 & 19845.000 & 0.668 & 4 & 0.465 \\
0.4 & 20580.000 & 0.663 & 4 & 0.477 \\
0.45 & 21002.100 & 0.685 & 4 & 0.494 \\
\hline
\end{tabular}

$0.2,0.25,0.3,0.35,0.4$, and 0.45 . The data are shown in Table 8 . Figures 11 to 14 are plotted by using the data from Table 8.

Figure 11 shows that $\delta$ has a significant influence on the total cost of the LSI. A larger $\delta$ corresponds to a larger $Z_{2}$. This conclusion is consistent with the conclusion of Liu et al. [1]. A larger $\delta$ corresponds to a greater $Z_{2}$ range, thus increasing the total cost.

Figure 12 indicates that $\delta$ has a certain influence on the CODP. The CODP moves forward to the second procedure with increasing $\delta$. A larger $\delta$ corresponds to a greater $Z_{2}$ range, which increases the procedure of the customization service and decreases the procedure of the mass service. Therefore, the CODP will move forward.

When $\delta<0.2, Z_{3}$ decreases along with increasing $\delta$, which is contrary to $\delta \geq 0.2$ (Figure 13). The relationship cost coefficient $\delta$ influences the customized degree positively when $\delta$ is greater than a certain value.

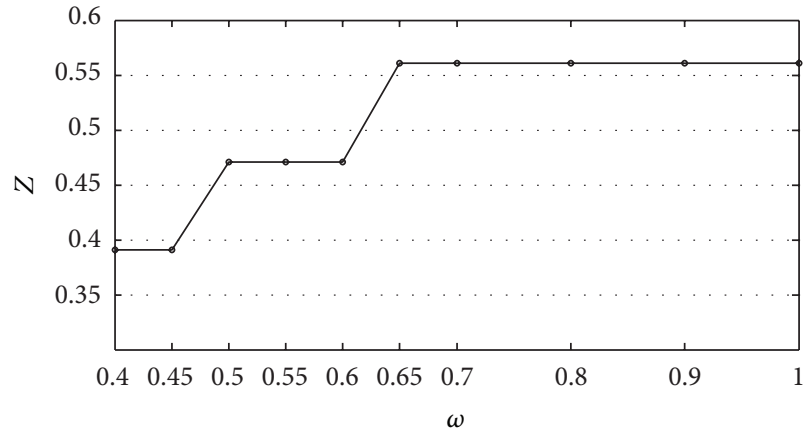

FIGURE 10: Influence of $\omega$ on $Z$ (comprehensive performance of LSSC).

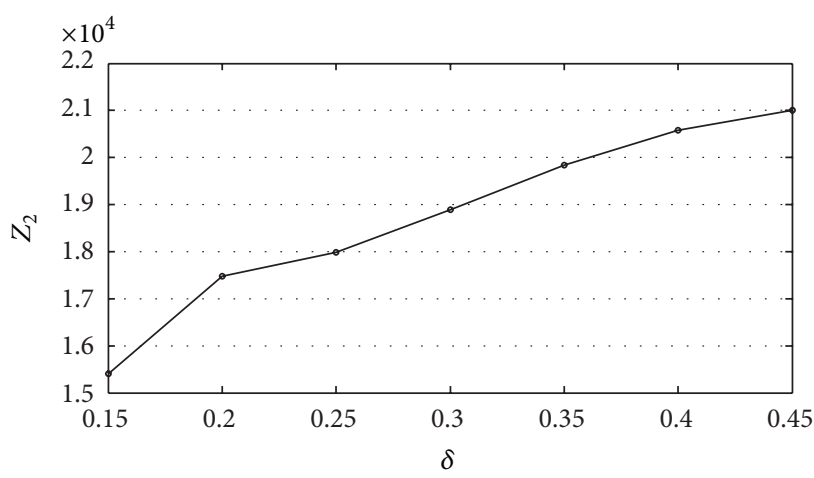

FIGURE 11: Influence of $\delta$ on $Z_{2}$ (total cost of LSI).

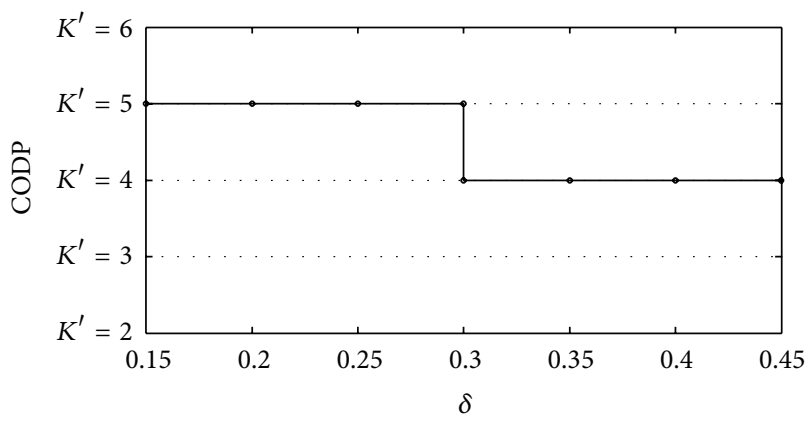

Figure 12: Influence of $\delta$ on CODP.

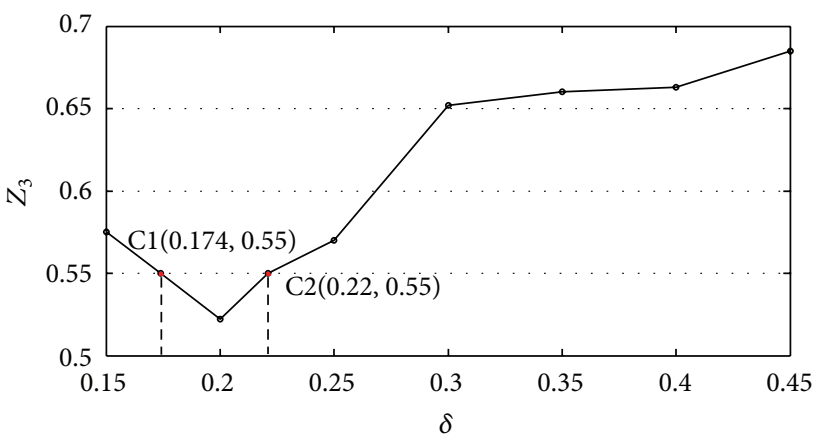

FIgURE 13: Influence of $\delta$ on $Z_{3}$ (customized degree). 
Further analysis shows that if the customized degree is greater than $0.575, Z_{3}$ increases with increasing $\delta$ (Figure 13). Thus, the LSI prefers to increase the value of $\delta$. However, when the customized degree is less than 0.575 , two $\delta$ s will be present. For this case, the LSI will prefer the smaller $\delta$. For example, when the customized degree is 0.55 , two $\delta$ will be present: $\mathrm{C} 1(0.174,0.55)$ and $\mathrm{C} 2(0.22,0.55)$ (Figure 13$)$. In this case, the LSI will choose $\mathrm{Cl}$.

Figure 14 shows that $Z$ decreases before increasing with increasing $\delta$. The breaking point is when $\delta=0.2$. This observation is different from previous studies that indicate that a greater $\delta$ corresponds to a looser constraint. Hence, $Z$ will increase.

This observation is attributed to the two parts of $Z$ : customized degree and satisfaction. Figure 13 shows that if $\delta$ is less than 0.2 , the customized degree decreases with increasing $\delta$. Consequently, $Z$ decreases. When $\delta$ is more than $0.2, Z$ increases with increasing customized degree (Figure 13).

Figure 14 shows that $Z$ only exhibits a positive correlation with $\delta$ when $Z$ is greater than 0.421 . When $Z$ is less than 0.421 , $Z$ initially decreases and then increases. When $Z$ is less than 0.421 , two $\delta$ 's are present. For this case, the LSI will prefer the smaller $\delta$. For example, when $Z$ equals 0.4 , two $\delta^{\prime}$ s exist: D1 $(0.18,0.4)$ and D2 $(0.22,0.4)$. In this case, the LSI will choose D1.

5.5. Relationship of Order Allocation Results and Related Factors. In this section, the relationship of order allocation results (total cost $Z_{2}$, customized degree $Z_{3}$, CODP, and comprehensive performance $Z$ ) and related factors (scale effect coefficient $\tau$, order difference tolerance coefficient $\omega$, and relationship cost coefficient $\delta$ ) is summarized.

\section{Main Conclusions and Management Insights}

In this section, we elaborate the main conclusions and implications for researchers. We also explore the management insights for LSI and FLSP and provide some suggestions.

6.1. Main Conclusions. On the basis of the analysis on Section 5, we obtained the following conclusions concerning order allocation under an MCLS environment.

(1) The total cost of LSI $Z_{2}$ decreases with increasing scale effect coefficient $\tau$ and increases with increasing order difference tolerance coefficient $\omega$ and relationship cost coefficient $\delta$. However, the influence of $\omega$ on $Z_{2}$ is finite. $Z_{2}$ becomes stable when $\omega$ increases to a certain value.

(2) The CODP moves back to the customers with increasing scale effect coefficient $\tau$ and moves forward to the second procedure with increasing order difference tolerance coefficient $\omega$ and relationship cost coefficient $\delta$. LSI can move the CODP forward and increase the customized degree by increasing the value of $\delta$. When $\tau$ is greater, the LSI prefers moving the CODP backward and acquiring the scale effect.

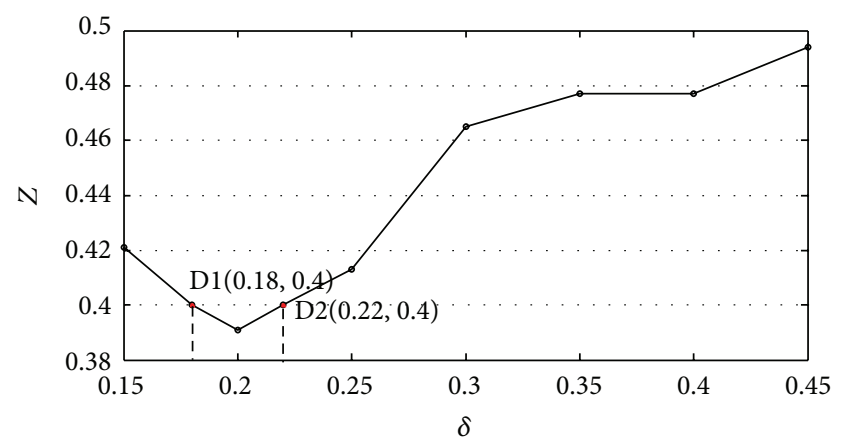

FIGURE 14: Influence of $\delta$ on $Z$ (comprehensive performance of LSSC).

(3) The customized degree $Z_{3}$ initially decreases before increasing with increasing scale effect coefficient $\tau$ and relationship cost coefficient $\delta$. When $Z_{3}$ is greater than a certain value, $\tau$ and $\delta$ have a positive correlation with $Z_{3} . \omega$ always has a positive influence on $Z_{3}$. When $\omega$ increases to a certain value, $Z_{3}$ tends to be stable.

(4) The comprehensive performance of order allocation $Z$ initially decreases before increasing with increasing scale effect coefficient $\tau$ and relationship cost coefficient $\delta$. When $Z$ is greater than a certain value, $\tau$ and $\delta$ have a positive correlation with $Z ; \omega$ always has a positive effect on $Z$. When $\omega$ increases to a certain value, $Z$ tends to be a stable.

6.2. Implications for Researchers. In line with academic research, this paper elaborates on the management of order allocation under the MCLS environment and the influences caused by allocation results. This paper provides a theoretical basis for the study of control methods about the performance of order allocation in MCLS. For instance, the type of order allocation method needs to be determined in choosing the FLSP. How will the comprehensive performance of the LSSC improve with minimum cost? How will the contradiction between cost and customization be solved? What factors have more influence on the comprehensive performance of the LSSC? This study provides the necessary theoretical basis for further research in the application and scheduling of the theoretical and empirical studies of LSSC under the MCLS environment.

6.3. Implications for Managers. LSI and FLSP managers should understand the factors that need focus and establish long-term strategic partnership for better cooperation.

The LSI should be careful in order allocation and choose the FLSP with a greater scale effect. The order difference tolerance factor should not be set extremely high. Excessive order difference tolerance results in a higher comprehensive performance of order allocation; however, excessive order difference tolerance can also lead to excessive total LSI cost. The order difference tolerance has a reasonable upper limit. Beyond this upper limit, the comprehensive performance of 
order allocation and the degree of customized experience initially decrease before increasing with increasing relationship cost coefficient. Therefore, a bigger relationship cost coefficient of the LSI does not indicate a better setup; instead, we should consider both the customized degree of the target and comprehensive performance.

For FLSP, the scale effect coefficient is important to enterprises for order allocation. Thus, enterprises need to improve large-scale operational capabilities continuously. When the comprehensive performance is high, FLSPs should request for cost compensation from the LSI by increasing the relationship cost coefficient, which improves FLSP satisfaction.

\section{Research Limitations and Future Work}

Under increasing customer demand for specialized and customized logistics services, the competitiveness of the LSSC depends on its ability to meet the need for customized requirements with the operating expense of mass service. The satisfaction of FLSPs will be maximized by minimizing the total cost of the LSI and maximizing the customized degree for customer demand. This paper establishes an order allocation model for the LSSC that is constrained by meeting the demand, CODP, and order difference tolerance coefficient. Numerical analysis is conducted with Lingo 12 software. The influences of the scale effect coefficient, order difference tolerance coefficient, and relationship cost coefficient on the order allocation and comprehensive performance of the LSSC are discussed. Management insights are also proposed.

However, the order allocation model also has some disadvantages. For instance, we assumed that each service process in order allocation requires only one service capability, such as transport service capability. In many cases, logistics service is the combination of different services including transportation, storage, loading, and unloading; each process may also be supported by a variety of capacities. The equivalent problem of each capacity needs to be considered in detail in the future. We also assumed that customer demand and service capacity are stable; however, customer demand may be random in actuality. Order allocation with random customer demand is an important direction for future studies. Furthermore, we assumed that the members of the LSSC have long-term cooperation, transparency, and mutual trust. In reality, we need to consider the game behavior among members because of its influence on order allocation. These problems need to be explored in detail in future research.

\section{Acknowledgment}

This research is supported by the National Natural Science Foundation of China (Grant no. 71372156), supported by Humanity and Social Science Youth Foundation of the Ministry of Education of China (Grant no. 2013YJC630098), and sponsored by China State Scholarship Fund and Independent Innovation Foundation of Tianjin University. The suggestions of the reviewers are also gratefully acknowledged.

\section{References}

[1] W. H. Liu, X. C. Xu, Z. X. Ren, and Y. Peng, "An emergency order allocation model based on multi-provider in two-echelon logistics service supply chain," Supply Chain Management, vol. 16, no. 6, pp. 391-400, 2011.

[2] C. Chandra and J. Grabis, "Managing logistics for mass customization: the new production frontier," in Proceedings of the World Automation Congress, vol. 18, pp. 335-340, July 2004.

[3] K. L. Choy, C. L. Li, C. K. SoS, L. Henry, S. K. Kwok, and D. W. K. Leung, "Managing uncertainty in logistics service supply chain," International Journal of Risk Assessment and Management, vol. 7, no. 1, pp. 19-43, 2007.

[4] R. I. van Hoek, "The rediscovery of postponement a literature review and directions for research," Journal of Operations Management, vol. 19, no. 2, pp. 161-184, 2001.

[5] H. Skipworth and A. Harrison, "Implications of form postponement to manufacturing a customized product," International Journal of Production Research, vol. 44, no. 8, pp. 1627-1652, 2006.

[6] W. Zinn and D. Bowersox, "Planning physical distribution with the principle of postponement," Journal of Business Logistics, vol. 19, no. 2, p. 117, 1988.

[7] J. C. P. Su, Y.-L. Chang, and M. Ferguson, "Evaluation of postponement structures to accommodate mass customization," Journal of Operations Management, vol. 23, no. 3-4, pp. 305-318, 2005.

[8] Y. H. Qin, "On delaying CODP to distribution center in mass customization," Communications in Computer and Information Science, vol. 152, no. 1, pp. 271-276, 2011.

[9] A. S. Dymond, S. Kok, and P. S. Heyns, "The sensitivity of multiobjective optimization algorithm performance to objective function evaluation budgets," in IEEE Congress on Evolutionary Computation, pp. 1868-1875, 2013.

[10] G. Gu, P. Fogla, D. Dagon, W. Lee, and B. Skoric, "Measuring intrusion detection capability: an information-theoretic approach," in Proceedings of the ACM Symposium on Information, Computer and Communications Security (ASIACCS '06), vol. 6, pp. 90-101, 2006.

[11] J. M. Yao and L. W. Liu, "Optimization analysis of supply chain scheduling in mass customization," International Journal of Production Economics, vol. 117, no. 1, pp. 197-211, 2009.

[12] F. Wang, J. Lin, and X. Liu, "Three-dimensional model of customer order decoupling point position in mass customisation," International Journal of Production Research, vol. 48, no. 13, pp. 3741-3757, 2010.

[13] H. Philip and H. C. G. Amos, "Dynamic implications of customer order decoupling point positioning," Journal of Manufacturing Technology Management, vol. 22, no. 8, pp. 1032-1042, 2011.

[14] P. M. J. Giesberts and L. van der Tang, "Dynamic of the customer order decoupling point: impact on information system for production control," Production Planning \& Control, vol. 3, no. 3, pp. 300-313, 1992.

[15] H. L. Lee and S. Christopher, "Modelling the costs and benefits of delayed product differentiation," Management Science, vol. 43, no. 1, pp. 40-53, 1997.

[16] G. Diwakar and S. Benjaafar, "Make-to-order, make-to-stock, or delay product differentiation? A common framework for modeling and analysis," IIE Transactions, vol. 36, no. 6, pp. 529546, 2004. 
[17] W.-H. Liu, S.-Y. Qu, and S.-Q. Zhong, "Order allocation in three-echelon logistics service supply chain under stochastic environments," Computer Integrated Manufacturing Systems, vol. 18, no. 2, pp. 381-388, 2012.

[18] W. H. Liu, Y. Yang, X. Li, H. T. Xu, and D. Xie, "A time scheduling model of logistics service supply chain with mass customized logistics service," Discrete Dynamics in Nature and Society, vol. 2012, Article ID 482978, 18 pages, 2012.

[19] F. T. S. Chan, P. K. Humphreys, and T. H. Lu, "Order release mechanisms in supply chain management: a simulation approach," International Journal of Physical Distribution and Logistics Management, vol. 31, no. 1, pp. 124-139, 2001.

[20] K. Matsuda, K. Yoshida, S. Sasaki, H. Yonekura, and M. Murakami, "Optimization of order allocation to in-stock slabs by genetic algorithm," Transactions of the Society of Instrument and Control Engineers, vol. 33, no. 2, pp. 118-126, 1997.

[21] W. Xie, F. S. Song, and F. F. Ye, "Order allocation for multiple supply-demand networks within a cluster," Journal of Intelligent Manufacturing, vol. 2, pp. 1-10, 2013.

[22] Azadeh, M. H. Khakbaz, and M. J. Songhori, "An integrated framework for supplier evaluation and order allocation in a non-crisp environment," International Journal of Logistics Systems and Management, vol. 6, no. 1, pp. 76-98, 2010.

[23] F. S. Song, W. Xiang, and F. F. Ye, "Order allocation model based on production load equilibrium for supply chain with multi-manufacturers and multi-suppliers," Applied Mechanics and Materials, vol. 101-102, pp. 763-767, 2012.

[24] W.-H. Liu, J.-H. Ji, and L. Zhou, "An order allocation model in two-echelon logistics service supply chain," Journal of Shanghai Jiaotong University, vol. 42, no. 9, pp. 1524-1533, 2008.

[25] K. Deb, "Solving goal programming problems using multiobjective genetic algorithms," in Proceedings of the Congress on Evolutionary Computation (CEC '99), vol. 1, pp. 77-84, 1999.

[26] L. Cheng and Y. G. Chen, "Strategy and method for multiobjective generation dispatch schedules," Automation of Electric Power Systems, vol. 36, no. 9, pp. 104-108, 2012.

[27] H. M. Srivastava and A. Y. Lashin, "Subordination properties of certain classes of multivalently analytic functions," Mathematical and Computer Modelling, vol. 52, no. 3-4, pp. 596-602, 2010. 


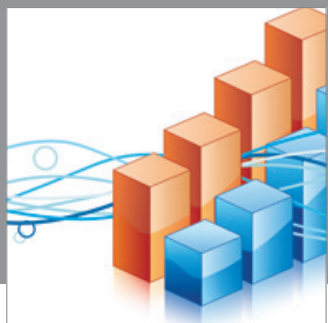

Advances in

Operations Research

mansans

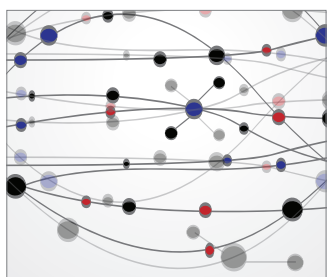

The Scientific World Journal
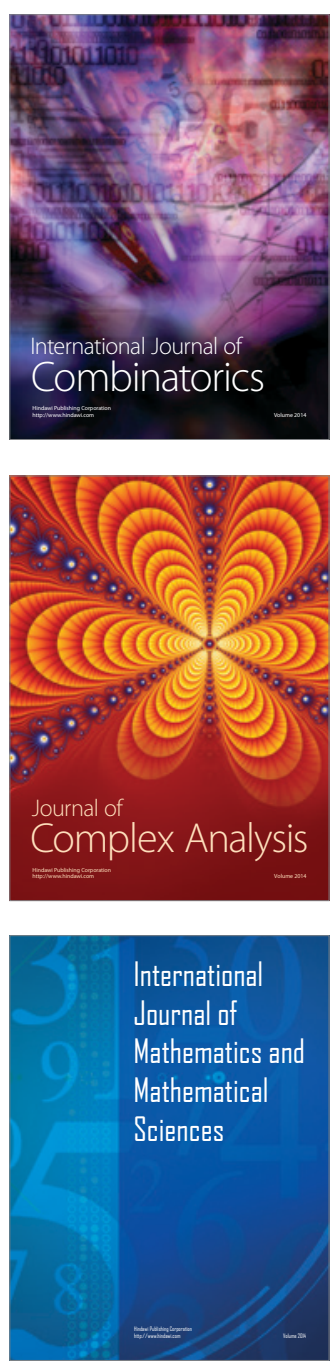
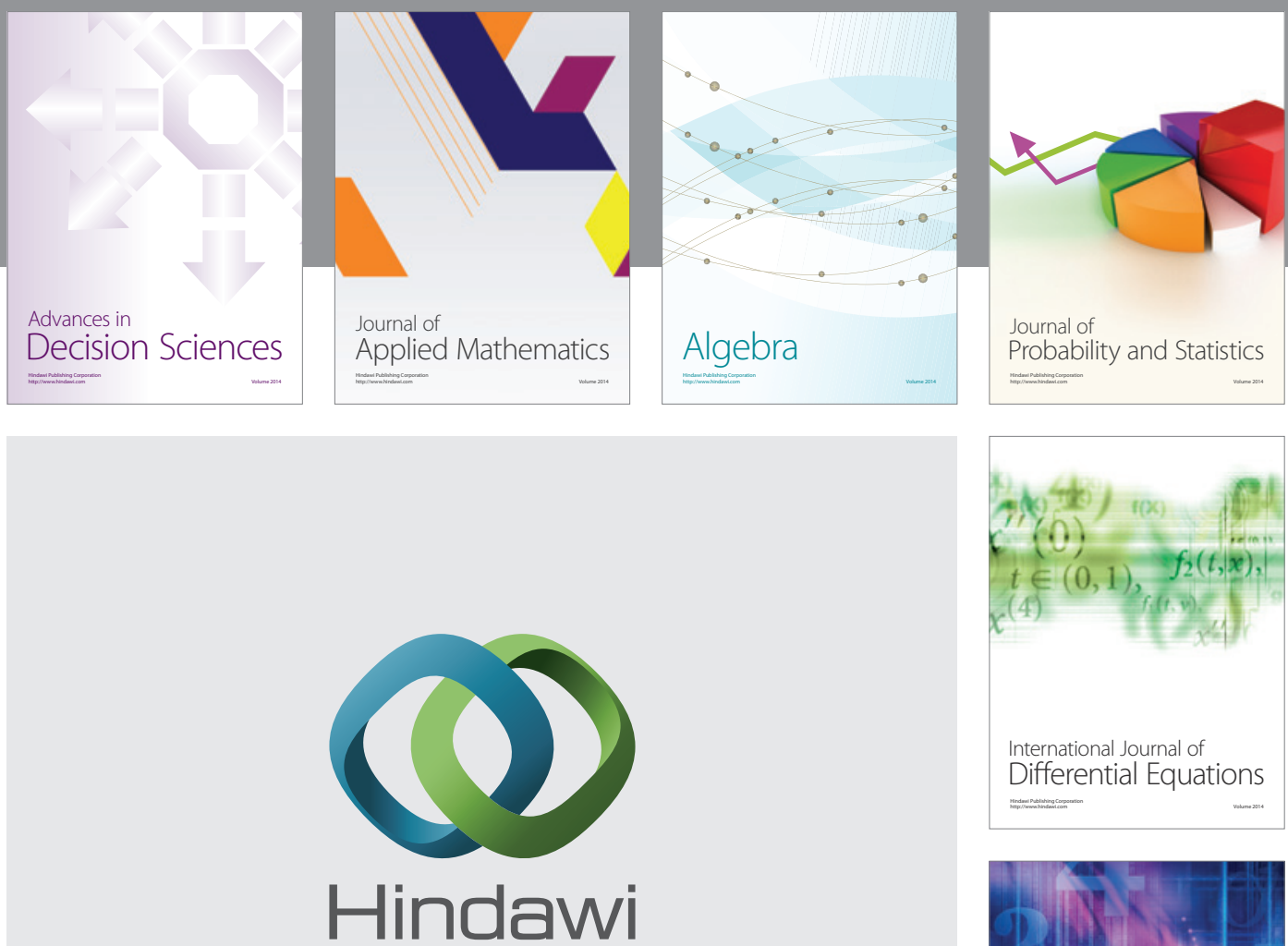

Submit your manuscripts at http://www.hindawi.com
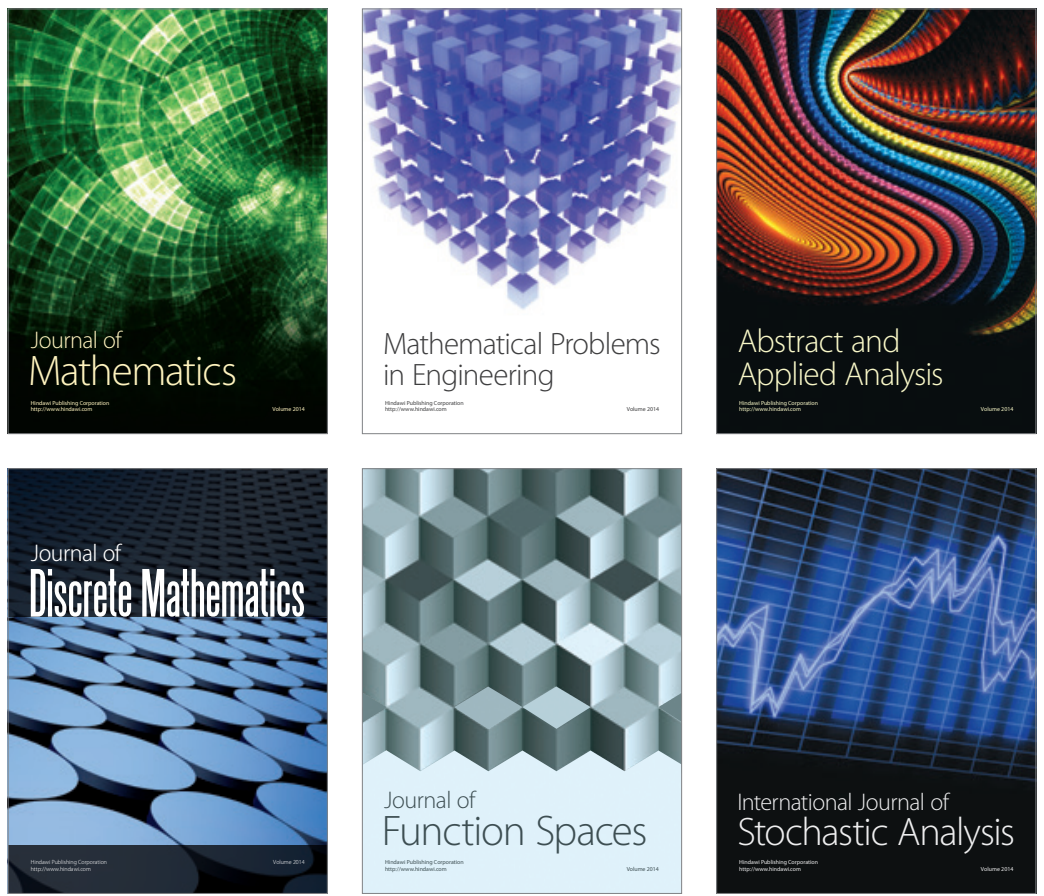

Journal of

Function Spaces

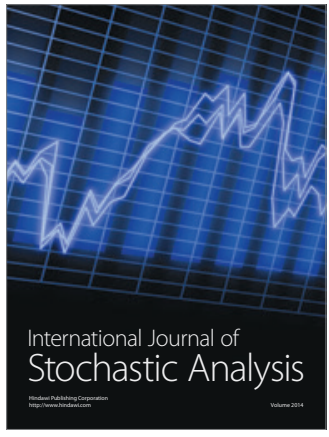

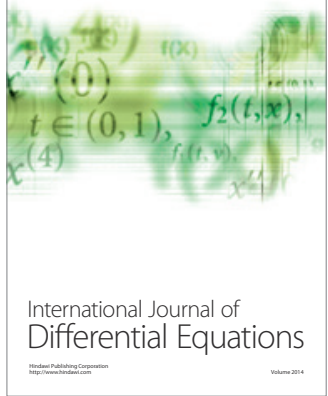
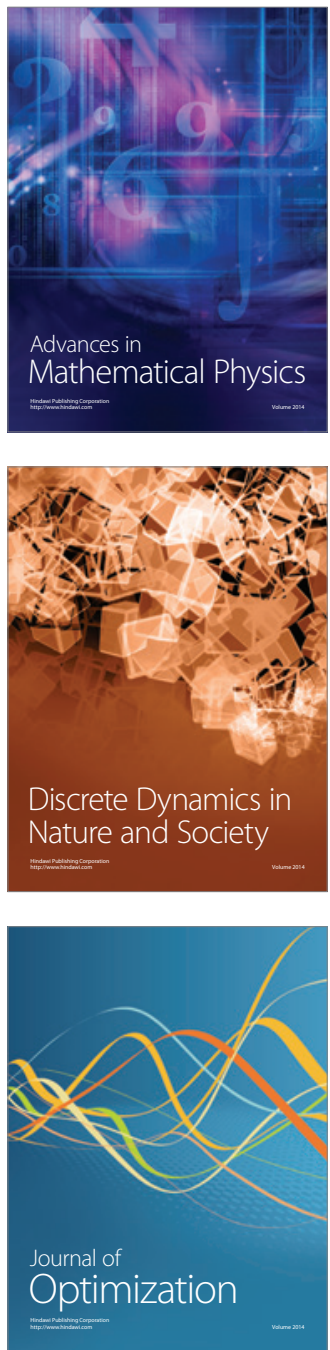